\title{
Sound production associated with reproductive behavior of Nassau grouper Epinephelus striatus at spawning aggregations
}

\author{
Michelle T. Schärer*, Timothy J. Rowell, Michael I. Nemeth, Richard S. Appeldoorn \\ Department of Marine Sciences, University of Puerto Rico, Mayagüez 00681, Puerto Rico
}

\begin{abstract}
Sound production by Nassau grouper Epinephelus striatus is described from different spawning aggregation sites in the Caribbean. Passive acoustic data and video were recorded in Belize (February 2011) and Puerto Rico (February 2012) revealing 2 distinctive sounds. The first is a pulse train sound thought to be associated with alarm or warning behavior, while the second is a tonal sound associated with reproductive behaviors, including courtship displays. The average peak frequency of the pulse train was $77.4 \pm 30.3 \mathrm{~Hz}$, individual pulse duration was $0.09 \pm 0.02 \mathrm{~s}$ and the number of pulses varied from 6 to 13. For the tonal sound, the average peak frequency was $99.0 \pm 33.6 \mathrm{~Hz}$, and sound duration was $1.6 \pm 0.3 \mathrm{~s}$, ranging from 0.9 to $2.3 \mathrm{~s}$. Long-term recordings at the Grammanik Bank, US Virgin Islands (February 2011) revealed variability in the daily patterns of tonal sounds during the residence time at the aggregation. Sound production was highest 7 to $8 \mathrm{~d}$ after the full moon between 20:00 and 21:00 h Atlantic Standard Time. The Nassau grouper courtship-associated sounds provide an advantageous tool to study the dynamics of spawning aggregations that are critical for the recovery of this Endangered species.
\end{abstract}

KEY WORDS: Sound production $\cdot$ Reproductive behavior $\cdot$ Courtship-associated sounds $\cdot$ Nassau grouper $\cdot$ Spawning aggregation $\cdot$ Passive acoustics

\section{INTRODUCTION}

The Nassau grouper Epinephelus striatus (Pisces: Epinephelidae) was previously one of the most commercially important coral reef species supporting fisheries in the Caribbean. Today it is considered as Endangered in the western Atlantic by the International Union for the Conservation of Nature (IUCN) due to steep declines in population size (Cornish \& Eklund 2003, Sadovy de Mitcheson et al. 2012). One of the main factors for this decline has been the collapse of spawning aggregations due to intense fishing pressure (Sadovy 1995, Sadovy \& Domeier 2005, Aguilar-Perera 2006).

Fish spawning aggregations (FSAs) are defined as a group of conspecific fish gathered to reproduce in numbers much higher than their density at other times (Domeier \& Colin 1997). Epinephelus striatus form site-specific transient aggregations, in which reproduction lasts for a period of days or weeks during a specific portion of the year (Domeier \& Colin 1997). These aggregations have been reported during the week of the full moon of December, January, and February (Colin 1992, Aguilar-Perera \& AguilarDávila 1996, Whaylen et al. 2006). Long-distance (up to $250 \mathrm{~km}$ ) spawning migrations have been reported for E. striatus (Carter 1989, Colin 1992), although it is not known how individuals locate aggregation sites. Additionally, Nassau grouper have been observed together with other species at multi-species FSAs (Claro \& Lindeman 2003, Nemeth et al. 2006, Whaylen et al. 2006, Heyman \& Kjerfve 2008, Schärer et al. 2012). Understanding the temporal and spatial dynamics of FSAs is essential to help restore the Endangered and Threatened species of groupers and to maintain coral reef fisheries. 
The main, if not all, reproductive effort for Nassau grouper occurs over very short time periods; therefore, all viable FSAs are crucial for the species' recovery. Historically, fewer than 100 Nassau grouper FSAs have been reported in the Caribbean, and up to one-third of these have diminished to negligible numbers or have ceased to form entirely (Sadovy \& Domeier 2005). Since there is no evidence that collapsed FSAs re-form at the same location (Beets \& Friedlander 1999, Aguilar-Perera 2006), protective measures for remaining FSAs are essential to enable the recovery of Nassau grouper populations.

Aspects of mating systems that occur during FSAs include the migration dynamics, timing, spawning stock abundance, and reproductive behaviors such as territoriality and courtship (Mann et al. 2010, Kline et al. 2011). The reproductive behaviors during FSAs of some groupers include changes in coloration (Archer et al. 2012), grouping of individuals, and intraspecific interactions that have been correlated with sound production (Mann et al. 2010, Nelson et al. 2011, Schärer et al. 2012). The recordings of sound produced by fish can serve as an indicator of aggregation formation, and sound has been described as an important component of reproductive behaviors for goliath grouper Epinephelus itajara (Mann et al. 2009), red grouper E. morio (Nelson et al. 2011), red hind E. guttatus (Mann et al. 2010), and yellowfin grouper Mycteroperca venenosa (Schärer et al. 2012). While the sound production capabilities of the closely related (Craig \& Hastings 2007) Nassau grouper have been established (Moulton 1958, Hazlett \& Winn 1962, Fish \& Mowbray 1970), sound production associated with FSAs has not been examined.

The purpose of the present study was to describe the characteristics of the sounds produced by Nassau grouper during spawning aggregations. Divers and an autonomous video camera with integrated passive acoustics recorded video of reproductive behaviors at 2 Nassau grouper FSA sites. Long-term passive acoustic data were collected at 2 different FSA sites where Nassau grouper have been reported. Video analysis provided the basis to identify sounds produced by Nassau grouper, and the physicalacoustic characteristics and the temporal patterns of sound production were made with the long-term recordings. With this information, complementary acoustic methods are proposed to help assess Nassau grouper reproductive activity, support research on the dynamics of FSAs, and employ appropriate protection of spawning aggregations of this Endangered species.

\section{MATERIALS AND METHODS}

\section{Study sites}

The study was conducted at 4 different spawning aggregation sites throughout the Caribbean (Fig. 1) during the Nassau grouper spawning season. The Glover's Reef (GR) Atoll, Belize $\left(16^{\circ} 44^{\prime} \mathrm{N}, 87^{\circ} 48^{\prime} \mathrm{W}\right)$, is 32 by $12 \mathrm{~km}$ and lies approximately $25 \mathrm{~km}$ east of the Mesoamerican Barrier Reef from which it is separated by depths of up to $400 \mathrm{~m}$, while the east side of the atoll drops to over $1000 \mathrm{~m}$. The Seasonal Closure Zone, covering an area of 1550 ha, encompasses the FSA site located on the northeast of the atoll (Sala et al. 2001). The spawning aggregation of Nassau grouper at this site has been reported from December through March, with a maximum count of 1000 Nassau grouper estimated in February 2011 (Coleman 2011).

Bajo de Sico (BDS) Bank, Puerto Rico (18 $14^{\prime} \mathrm{N}$, $67^{\circ} 26^{\prime} \mathrm{W}$ ), is a submerged seamount approximately $27 \mathrm{~km}$ west of Puerto Rico, surrounded by depths of over $250 \mathrm{~m}$ to the southeast near the Puerto Rico insular shelf and over $1000 \mathrm{~m}$ to the north. Currently, there is a 6 mo seasonal closure to all fishing from October to March of each year. Although Nassau grouper have been reported from BDS (García-Sais

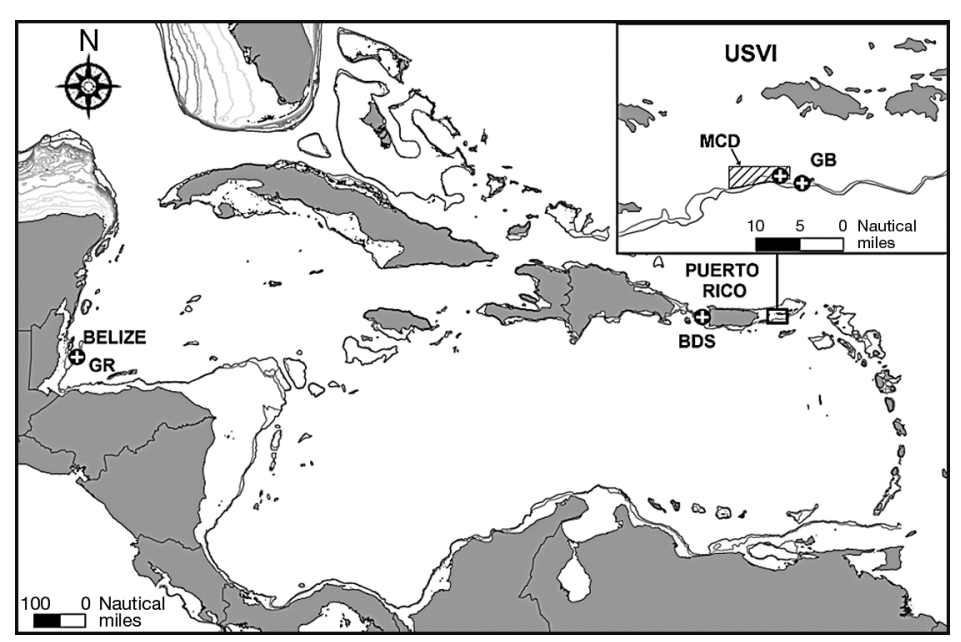

Fig. 1. Fish spawning aggregation (FSA) sites where passive acoustic data were recorded: Glover's Reef (GR), off the coast of Belize; Bajo de Sico (BDS), west of Puerto Rico; and (inset) Hind Bank Marine Conservation District (MCD) and Grammanik Bank (GB), both south of the US Virgin Islands (USVI). Grey lines indicate bathymetry contours $<500 \mathrm{~m}$ 
et al. 2007), the spawning season for this particular site remains unknown. The location of the aggregation was pinpointed for the first time during the present study when at least 60 individuals were observed exhibiting reproductive behaviors in February 2012.

The Hind Bank Marine Conservation District (MCD) is located on the southern edge of the Puerto Rican Shelf within the US Caribbean exclusive economic zone (EEZ), approximately $12 \mathrm{~km}$ south of St. Thomas, US Virgin Islands (USVI), and extends westwards into the southeastern extent of the Virgin Passage. This site encompasses a multi-species spawning aggregation with an area of $41 \mathrm{~km}^{2}$ (Nemeth 2005). The area was closed to fishing seasonally in 1990 and closed permanently in 1999 to protect an important Epinephelus guttatus aggregation and to recover an extirpated E. striatus spawning aggregation (Olsen \& La Place 1978, Nemeth 2005). Formation of a spawning aggregation had been documented at this site from December through February for both species (Olsen \& La Place 1978).

The Grammanik Bank (GB), USVI, is located approximately $3 \mathrm{~km}$ east of the MCD on the southern edge of the Puerto Rican Shelf $\left(18^{\circ} 11^{\prime} \mathrm{N}, 64^{\circ} 57^{\prime} \mathrm{W}\right)$ and extends $1.7 \mathrm{~km}$ at its maximum length. The bank is bordered to the north by another coral bank and to the south by the steep drop-off. GB is located in the US Caribbean EEZ, and fishing is prohibited from February to April of each year to protect yellowfin grouper during their spawning aggregation. Since 2004, approximately 100 Nassau grouper were observed aggregating at this site from January through March, although spawning has not been documented (Nemeth et al. 2006).

\section{Video and audio recordings}

The autonomous audio/video recorder system is made up of a low-light camera and digital recorder within a PVC housing with 2 external hydrophones (Schärer et al. 2012). Audio is saved as 16-bit .wav files at a sample rate of $44100 \mathrm{~Hz}$. The autonomous audio/video recorder system was calibrated by generating $0.1 \mathrm{~V}$ peak test sine waves at $10,20,50,100$, $150,200,400,700,1000$, and $1500 \mathrm{~Hz}$, and determining the frequency response. The frequency response was used to construct a custom finite-duration impulse response (FIR) filter.

The video camera was set on a tripod on the seafloor facing upwards at an angle of approximately $45^{\circ}$ and remained there for a period of up to $24 \mathrm{~h}$ at 2 different Nassau grouper FSA sites (GR and BDS). Two consecutive deployments were made on February 21 and 22, 2011 (3 and $4 \mathrm{~d}$ after the full moon [DAFM]) at GR by placing the camera at a depth of $40 \mathrm{~m}$ within a group of approximately 1000 Nassau grouper. Video and audio were recorded during the afternoon hours (after 15:00 h) and only audio after sunset. A third deployment was made on February 18, 2012 (11 DAFM) at BDS, where Nassau grouper were aggregated at 40 to $50 \mathrm{~m}$ depth. The camera was deployed at noon $(12: 00 \mathrm{~h})$ and recorded video and audio until sunset and continuous audio through the night.

Video and audio recordings were viewed on a computer while listening with headphones to identify and characterize the sounds and behaviors of Nassau grouper. Observations lasted $10 \mathrm{~s}$ before and after each sound, and included abundance of Nassau grouper, display coloration patterns, and a description of behavior during sound production. Audio files containing sounds where Nassau grouper occurred were isolated, resampled to $4410 \mathrm{~Hz}$ using MATLAB, and corrected with the unique FIR filter. Nassau grouper sounds with high signal-to-noise ratios were analyzed and characterized with a custom MATLAB program (HotWav). HotWav applied a high-pass filter at $30 \mathrm{~Hz}$ and a low-pass filter at $500 \mathrm{~Hz}$, with $5 \mathrm{~Hz}$ of resolution, and calculated peak frequency, duration, and $3 \mathrm{~dB}$ bandwidth for each sound. Spectrograms were generated (Adobe Audition) to visualize the physical patterns of sounds, which were then used along with the characterization statistics to identify and isolate sounds from the long-term passive acoustic data recorded at USVI. Additional diver-operated video cameras were used at BDS to document the presence of sounds generated by Nassau grouper in relation to fish behaviors.

\section{Passive acoustic recordings}

Long-term audio recording devices were deployed at 2 different spawning aggregation sites in the USVI (MCD and GB). A digital spectrogram recorder (DSG-Ocean, Loggerhead Instruments) was attached $\sim 2 \mathrm{~m}$ above the seafloor to a line with a submerged float at a depth of approximately $40 \mathrm{~m}$. Passive acoustic recordings were made from 22 February to 2 March $(13 \mathrm{~d})$, with a recording interval of $20 \mathrm{~s}$ every $5 \mathrm{~m}$. Each DSG-Ocean unit consists of a cylindrical PVC housing, a single HTI-96-MIN hydrophone, microcomputer, and circuit board, and was powered by Dcell alkaline batteries. Single-channel audio was recorded and digitized at a sample rate of $9523 \mathrm{~Hz}$ onto a 32-gigabyte digital flash memory card. 
Data files were manually inspected by displaying each as a spectrogram to detect sounds similar to those recorded with video for Nassau grouper. These were manually isolated and quantified from the GB and MCD recordings. Furthermore, the files with high signal-to-noise ratio were analyzed with HotWav as previously described (see 'Video and audio recordings') for physical characterization. The mean, standard deviation (SD), minimum and maximum peak frequency, duration, and $3 \mathrm{~dB}$ bandwidth were calculated from the Nassau grouper sounds analyzed from GR, BDS, GB, and MCD. Spectrogram (700 point Fast Fourier Transform [FFT], no overlap, Hann window) and oscillogram figures were generated from typical calls recorded at GB and GR in MATLAB.

In order to determine temporal patterns in sound production, the Nassau grouper sounds in each $20 \mathrm{~s}$ (.wav) file recorded at GB were quantified. The tonal sounds were detected by visually utilizing spectrograms generated in Ishmael 2.0 software with a 1024 FFT Hann window and verified audibly. The number of tonal sounds per $20 \mathrm{~s}$ was averaged per hourly interval over the February 2011 spawning period (4 to 12 DAFM). Non-parametric multiple comparison Kruskal-Wallis ANOVA and medians tests were performed in order to differentiate the peak temporal units of sound production.

\section{RESULTS}

\section{Video and audio recordings of Nassau grouper}

At GR, the Nassau grouper spawning aggregation was filmed with the autonomous video/audio recorder on 2 consecutive days. These recordings primarily consisted of video images of Nassau grouper, with fewer appearances by tiger grouper Mycteroperca tigris and yellowfin grouper as well as schools of white margate Haemulon album. We observed all 4 coloration patterns or phases that have been described for Nassau grouper during spawning aggregations, including the bi-color phase, which is associated with peak spawning times (Colin 1992, Archer et al. 2012). The diversity of sounds produced at this spawning aggregation was high, including some produced by coral reef fish that have been recorded previously, including squirrelfish Holocentrus adscensionis (Moulton 1958) and toadfish Sanopus astrifer (Mann et al. 2002), although these were not visible in video images. During the first deployment (3 DAFM), Nassau grouper occurred 10 to $25 \mathrm{~m}$ above the sea- floor in a continuous school. A maximum count of 100 Nassau grouper per video sequence was made as they swam in 1 consistent direction. On the second deployment (4 DAFM), the abundance of fish was similar to the day before, but also included reproductive behaviors such as following and circling (Colin 1992). Following occurred when 2 or more Nassau grouper were swimming in the same direction or milling as a larger group, while those that circled laterally or vertically over another individual were categorized as exhibiting circling behavior. Bi-color Nassau grouper were seen nudging individuals with white ventral coloration, and interactions between fish of all color phases were sometimes accompanied by a short tonal sound preceded by a variable number of pulses. The tonal sound was regularly produced during courtship behaviors described above (following or circling as per Colin 1992), and was also heard after sunset, yet no spawning rushes were seen.

At BDS, Nassau grouper were recorded with the autonomous audio/video system overnight on 1 occasion (11 DAFM) during the last evening of the February peak of the spawning aggregation. Other species sounds were also detected, including squirrelfish (Moulton 1958), red hind (Mann et al. 2010), and yellowfin grouper (Schärer et al. 2012), although they were not seen in the video. During this deployment, Nassau grouper courtship behaviors were observed when the tonal sound was detected. A maximum of 12 Nassau grouper were seen following and circling in video images, and at 17:00 h, a maximum of 2.5 tonal sounds $\mathrm{min}^{-1}$ was heard within a 15 min continuous video/audio file.

At BDS, a less common pulse train sound was identified and recorded by a diver on a handheld GoPro video camera. This pulsing sound was heard as divers approached Nassau grouper near the bottom or chased them into crevices. This type of sound production was also occasionally recorded on audio-only deployments at BDS and GB, but the only time audio and video recordings of this pulse train coincided was the case of human interaction at BDS.

\section{Physical parameters of sound}

Two types of sounds associated with Nassau grouper were isolated from the autonomous audio/ video recordings from GR and BDS as well as from the long-term passive acoustic recordings from MCD and GB. The pulse train (Fig. 2a,b) is made up of a varying number of short individual pulses. The sec- 
ond type, the tonal sound (Fig. 2c,d), was heard more often, and coincided with courtship behavior observed in video recordings, hence classified as a courtshipassociated sound (CAS; Lobel \& Kerr 1999). The CAS was variable in the number of short pulses that preceded the characteristic and longer tonal portion of the sound.

The pulse train alarm sounds $(\mathrm{n}=10)$ recorded at GR and BDS were subdivided into individual pulses ( $\mathrm{n}=91$ ) for acoustic characterization, since the number of pulses per call varied. Recordings from GB and MCD did not yield any high signal-to-noise ratio pulse train sounds during the study period, and therefore, were not included in this characterization. The average peak frequency was $77.4 \pm 30.3 \mathrm{~Hz}$ (minimum: $36.3 \mathrm{~Hz}$, maximum: $169.1 \mathrm{~Hz}$ ), and the average $3 \mathrm{~dB}$ bandwidth was $55.9 \pm 29.5 \mathrm{~Hz}$ (minimum: $10.2 \mathrm{~Hz}$, maximum: $165.7 \mathrm{~Hz}$ ). Individual pulse duration was $0.09 \pm 0.02 \mathrm{~s}$ (minimum: $0.6 \mathrm{~s}$, maximum: $0.11 \mathrm{~s}$ ). The number of pulses per pulse train varied from 6 to 13 .

Tonal sounds with high signal-to-noise ratios $(\mathrm{n}=95)$ were recorded at all study sites and were included in the acoustic characterization. The acoustic pattern was visually recognizable, with a short burst or two at the beginning, which was not always present, followed by a tonal segment that was more consistent. The average peak frequency was $99.0 \pm 33.6 \mathrm{~Hz}$ (minimum: $50.8 \mathrm{~Hz}$, maximum: $206.0 \mathrm{~Hz}$ ), the average $3 \mathrm{~dB}$ bandwidth was $22.4 \pm$
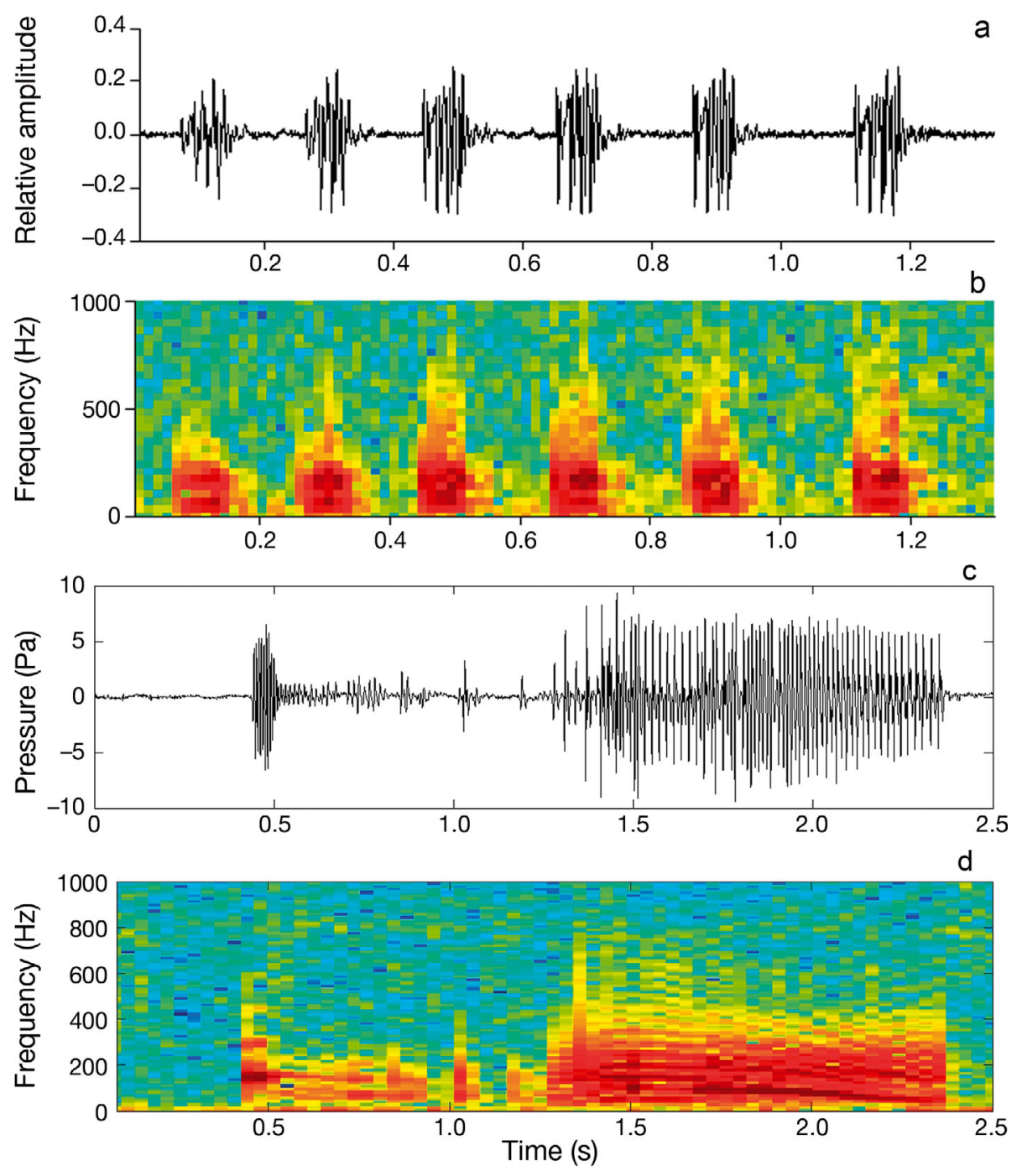

Fig. 2. Epinephelus striatus. (a) Oscillogram and (b) spectrogram of pulse train sound from Glover's Reef (GR) ( $y$-axis is relative amplitude since audio was extracted from video files; Fast Fourier Transform [FFT] size 128, no overlap). (c) Oscillogram and

(d) spectrogram of tonal sound from Grammanik Bank (GB) (FFT size 700, no overlap). For site locations see Fig. 1 
12.2 Hz (minimum: $4.3 \mathrm{~Hz}$, maximum: $53.7 \mathrm{~Hz}$ ), and average sound duration was $1.6 \pm 0.3 \mathrm{~s}$ (range: 0.9 to $2.3 \mathrm{~s})$. The maximum received sound level for the tonal call was $143 \mathrm{~dB}$ re $1 \mu \mathrm{Pa}$.

\section{Temporal patterns in sound production}

Temporal patterns in CAS were analyzed at GB, because few Nassau grouper tonal sounds were recorded at $\mathrm{MCD}$ and the long-term DSG recorders were not used at GR or BDS. At GB, Nassau grouper CAS production varied significantly, both hourly and daily, revealing distinct temporal patterns. Peak days of sound production occurred the week after the full moon (4 to 12 DAFM) in February 2011. The highest count of CAS was detected from 7-9 DAFM, followed by a continuous decline until 12 DAFM, when CAS dropped to near zero (Fig. 3). The count of CAS per 20 s averaged throughout the day was significantly higher on 7, 8, and 9 DAFM when compared to 12 DAFM (Kruskal-Wallis test: $H=99.62268, \mathrm{p}<0.01$ ). On all days between 4 and 12 DAFM, significant differences in mean CAS of hourly intervals were detected; however, no consistent diel pattern was observed among the days of highest sound production (Fig. 4). The highest mean values of CAS were at 20:00 h Atlantic Standard Time (AST), approximately $1.5 \mathrm{~h}$ after sunset, on the 7 th and 8th DAFM (Fig. 4c,d).

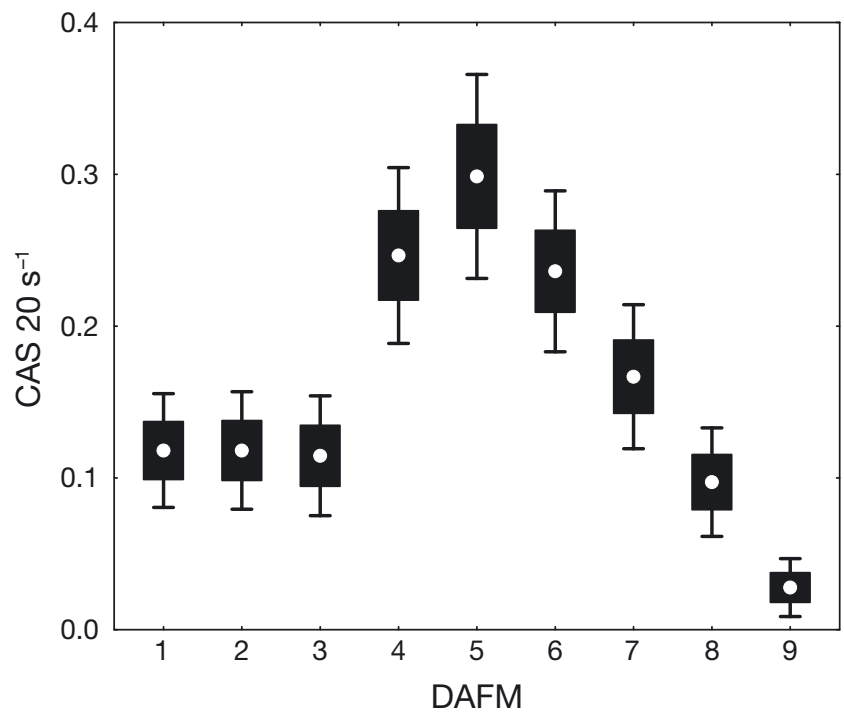

Fig. 3. Epinephelus striatus. Mean number of courtship-associated sounds (CAS) per $20 \mathrm{~s}$ for days after the full moon (DAFM) from recordings at Grammanik Bank (GB) in February 2011. Boxes show limits of SE around the mean (white circles); whiskers show $95 \%$ confidence limits. For site location see Fig. 1
At this hour interval, the mean CAS per $20 \mathrm{~s}$ was 3.4 and 4.2 times higher respectively than the mean of the other days analyzed during that time interval. This difference in CAS for the 20:00 h AST interval between days was significant (Kruskal-Wallis test: $H$ $=33.69039, \mathrm{p}<0.01$ ) on 7 and 8 DAFM compared to 12 DAFM.

\section{DISCUSSION}

During incipient fish acoustic research conducted in the marine environment, Nassau grouper were reported as important sound-producing coral reef fish due to their characteristic call (Moulton 1958). Their alarm call can be heard underwater without amplifiers, and is produced by the contraction of a sonic muscle located behind the opercle connecting the vertebrae with the air bladder (Moulton 1958, Fish \& Mowbray 1970). This pulsing sound was reported as a response to specific stimuli, such as divers or other artifacts, such as surface-deployed hydrophones (Moulton 1958), approaching a fish, causing it to flee, or when under duress, including handling and electric stimulation (Hazlett \& Winn 1962, Fish \& Mowbray 1970). During the present study, we associated this pulse train alarm sound with distress, alarm, or warning, based on a limited number of observations and reports from experienced spear fishers. However, further research is necessary to determine its significance during spawning aggregations, since it was heard without any human presence in autonomous recordings.

Hazlett \& Winn (1962) described the acoustical characteristics of Nassau grouper alarm sounds ranging from 85 to $2000 \mathrm{~Hz}$, with most falling below $600 \mathrm{~Hz}$. The duration (0.05 to $0.124 \mathrm{~s})$ of the alarm sound reported by Hazlett \& Winn (1962) is similar to that reported by Moulton (1958) and the individual pulses of the alarm sound recorded during the present study. The recordings collected in the present study varied in duration by up to a factor of 2, suggesting that the pulse trains are highly variable, while the pulses themselves are very similar (Fig. 2a,b).

During spawning aggregations, Nassau grouper produce a second distinctive type of tonal sound, which, based on in situ audio and video recordings, can be considered a CAS. Tonal sounds were produced while 2 or more individuals were seen engaging in courtship, which sometimes was accompanied by ephemeral changes in body coloration (i.e. bicolor pattern) or during interactions with distended, pre- 

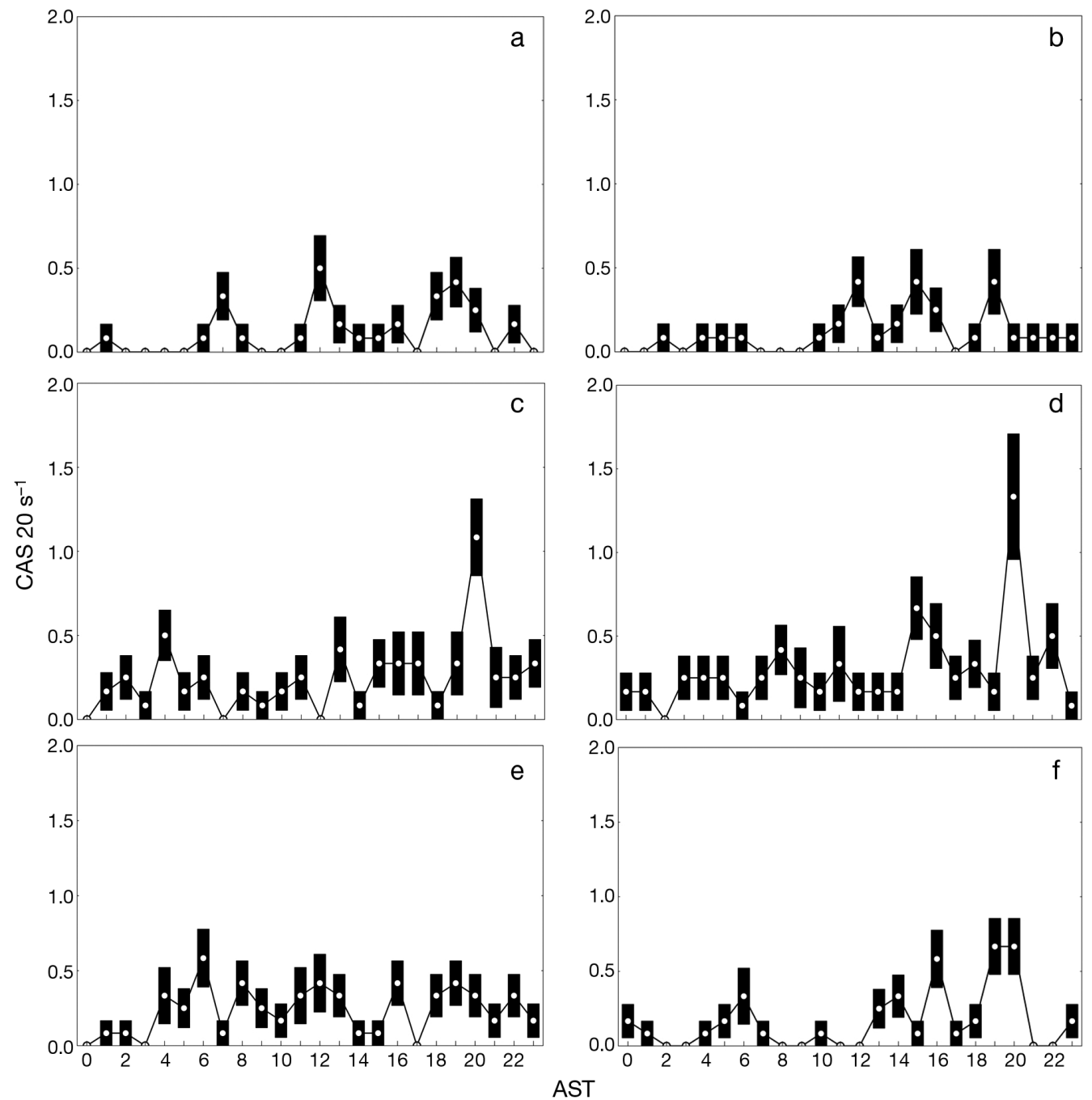

Fig. 4. Epinephelus striatus. Mean number (SE) of courtship-associated sounds (CAS) per 20 s during hourly intervals (Atlantic Standard Time, AST) per day: (a) 5 d after the full moon (DAFM), (b) 6 DAFM, (c) 7 DAFM, (d) 8 DAFM, (e) 9 DAFM, and (f) 10 DAFM at Grammanik Bank (GB) during February 2011. For site location see Fig. 1

sumably gravid female Nassau grouper. Changes in color patterns have been described as signals of submission in territorial encounters at spawning aggregations (Colin 1992, Archer et al. 2012), and tonal sounds appear to be an important component of Nassau grouper communications. This type of interaction between individuals may be related to readiness to spawn or a form of social behavior to synchronize spawning. Here we propose that CAS are a significant component of Nassau grouper reproductive behavior and may indicate social interactions leading to spawning. Therefore, CAS can be used to deduce reproductive activity and identify temporal patterns of FSA, which is essential for the establishment of protective measures.
Sound production has been associated with reproduction in other marine fishes (Lobel 2002), such as groupers Epinephelus guttatus (Mann et al. 2010), E. morio (Nelson et al. 2011), and Mycteroperca venenosa (Schärer et al. 2012); damselfish Stegastes partitus (Myrberg et al. 1986, 1993), Abudefduf sordidus (Lobel \& Kerr 1999), and Dascyllus albisella (Mann \& Lobel 1998); toadfish Sanopus astrifer (Mann et al. 2002); black drum Pogonias cromis (Locascio \& Mann 1986); and a marine croaker Kathala axillaris (Veerappan et al. 2009). Sound production in the reproductive context serves in species recognition (Myrberg et al. 1993), mate attraction (Veerappan et al. 2009), sex selection (Myrberg et al. 1993), and courtship (Lobel \& Kerr 1999, Schärer et al. 2012), 
which are significant components of reproductive behavior. It remains to be determined if Nassau grouper can discern differences in the physical characteristics of sounds in order to select individuals for spawning or recognize conspecifics during multispecies aggregations. The increase in sound production during the progression of the aggregation may serve to attract and concentrate the spawning stock via social interactions. Sound in combination with color displays and other reproductive behaviors may be a proximate cue for egg hydration, which is essential for synchronous spawning during the few days of peak abundance at the FSA.

The physical parameters of Nassau grouper tonal sounds were similar to, but distinct from, other tropical western Atlantic groupers that tend to co-occur in multi-species spawning aggregations. The duration of CAS produced by Nassau grouper was similar to red hind (Mann et al. 2010) and red grouper (Nelson et al. 2011), yet less than that reported for yellowfin grouper (Schärer et al. 2012), although significant variability has been seen for the latter. Peak frequency of Nassau grouper tonal sounds was lower than for red hind (Mann et al. 2010), yet higher than for goliath grouper (Mann et al. 2009), as expected due to differences in body size. Moreover, with practice it is possible for humans to distinguish between the CAS produced by Nassau grouper and the sounds of closely related species by studying the sounds visually in spectrograms and audibly. In the field, the sound of the Nassau grouper could be heard up to $200 \mathrm{~m}$ away in areas with little or no structure. However, if background noise is above $100 \mathrm{~dB}$, there may be interference affecting the ability to detect these sounds. Therefore, sound pollution may be another threat affecting this critical phase of the Nassau grouper's life cycle.

Temporal patterns of Nassau grouper CAS can help elucidate the dynamics of their spawning aggregations. Although the spawning season for Nassau grouper has generally been reported as December through February (Colin 1992), there has been variability as to the peak spawning month, which may be related to temperature and lunar phase (Sadovy \& Eklund 1999). The long-term passive acoustic data suggest that Nassau grouper aggregated on the same lunar schedule through March at BDS and through May at GB (T. J. Rowell unpubl. data), which is supported by field observations at the latter site (Nemeth et al. 2006, Kadison et al. 2010). At GB, Nassau grouper are occupying the same areas as yellowfin grouper during aggregation months, and it may be possible that interactions between species are causing Nassau grouper to remain at the site later in the season, although spawning has not been observed for Nassau grouper to date (Kadison et al. 2010). Another hypothesis may be the timing of water temperature at which spawning has been reported (25 to $26^{\circ} \mathrm{C}_{i}$ Sadovy \& Eklund 1999). Differences in peak spawning occurrence must be investigated further in order to ensure effective seasonal protections at the regional scale, since the Nassau grouper population of the eastern Puerto Rican platform stretches across international boundaries (i.e. British Virgin Islands), where the species is protected during a limited season (March through May).

At GB during February 2011, Nassau grouper CAS production indicated $8 \mathrm{~d}$ of residence and 3 nights of intense reproductive behavior, which is similar to that reported in previous years at GB (Kadison et al. 2010), and also to the Little Cayman Island Nassau grouper aggregation, with $9 \mathrm{~d}$ of residence and peak spawning between 4 and 7 DAFM (Archer et al. 2012). The precise days of spawning in relation to the full moon vary from year to year, yet spawning has been documented 24 to $48 \mathrm{~h}$ after reaching maximum numbers in abundance (Whaylen et al. 2006), along with increases in the proportion of bi-color Nassau grouper prior to peak spawning (Archer et al. 2012). During the present study, drastic increase in CAS during 2 days (Fig. 4) suggests that a similar increase in reproductive behaviors may be occurring prior to peak spawning. The relationship between CAS and spawning requires long-term recordings coupled with visual observations of abundance and spawning.

Diel patterns with highest sound production in late afternoon to after sunset have been reported in sciaenids (Locascio \& Mann 2011) and epinephelids (Mann et al. 2010, Nelson et al. 2011, Schärer et al. 2012). Nassau grouper at GB showed a peak in CAS $1.5 \mathrm{~h}$ after sunset, but only on 7 and 8 DAFM, while on other days, no consistent trend was observed (Fig. 4). Therefore, the passive acoustic monitoring of Nassau grouper FSAs cannot depend on a restricted period of data collection, as proposed for red hind (Rowell et al. in press).

There is no information available regarding the reproductive behavior of Nassau grouper after sunset that can be used to elucidate how CAS diel patterns are related to spawning. Long-term acoustic data from other aggregations dominated by Nassau grouper are necessary to determine if the temporal patterns in CAS are site-specific, depending on factors such as spawning stock size, additional species 
present, geographic setting, and others. For example, temporal patterns of CAS for red hind suggested different peak spawning days between 2 FSAs west of Puerto Rico and $49 \mathrm{~km}$ apart (Mann et al. 2010). Moreover, Nassau grouper spawning aggregations may have an abundance threshold under which reproductive behaviors are reduced, affecting spawning success (Colin 1992). Therefore, variability in spawning activity could be detected with passive acoustics and compared between FSAs of different abundances to measure differences that may be related to their viability.

Underwater visual census methods used to monitor spawning aggregations are affected by a variety of factors, including remoteness of locations, inclement weather, water visibility, and other resource limitations. Rapid changes in fish abundance over a few days require daily underwater surveys to track changes in the spawning stock during peak spawning days (Colin 2012). Knowing this time span will help improve estimates of spawning stock for each site and can be species-specific. Passive acoustic recordings provided data on the presence, residence time, reproductive activity levels, and location of spawning aggregations, which are all essential criteria for their protection. Based on the results of the present study and other recent studies (Mann et al. 2010, Rowell et al. 2012), sounds provide an alternate or complementary method for studying Nassau grouper spawning aggregations in situ with minimal interference and reduced effort. However, given the dispersion and detection range for Nassau grouper sounds, the recording instruments need to be located within $200 \mathrm{~m}$ of the aggregation, or even closer in high-relief habitats such as coral reefs. Additionally, shifts in the exact location of spawning sites may occur (Colin 1992, Aguilar-Perera 2006), and this needs to be considered when designing any FSA monitoring program.

Sound seems to be an important aspect of fish communication during spawning aggregations, and the study of these acoustic characteristics may enhance our understanding of the role of sound in the reproductive ecology of groupers. The application of this technology to the conservation of Nassau grouper as well as other Endangered groupers with this reproductive strategy has the potential to augment monitoring and the detection of unknown FSAs. Given the state of this Endangered species in the western Atlantic, conserving spawning aggregations is a necessary condition for its recovery, and passive acoustic techniques can be applied to design and evaluate protective measures.
Acknowledgements. Invaluable assistance in the field was provided by the following scientific divers: D. MateosMolina, E. Tuohy, J. Rivera, and the crew of 'Tourmarine', Cabo Rojo. We acknowledge the Wildlife Conservation Society marine research station at Glover's Reef, Belize, especially V. Burns, and the staff of University of the Virgin Islands, St. Thomas, USVI, particularly R. Nemeth and E. Kadison. Technical assistance from D. Mann and M. Nelson was essential for data processing and sound characterization. Figures were enhanced thanks to H. Ruiz, and anonymous reviewers provided suggestions that improved this manuscript.

\section{LITERATURE CITED}

Aguilar-Perera A (2006) Disappearance of a Nassau grouper spawning aggregation off the southern Mexican Caribbean coast. Mar Ecol Prog Ser 327:289-296

Aguilar-Perera A, Aguilar-Dávila W (1996) A spawning aggregation of Nassau grouper Epinephelus striatus (Pisces: Serranidae) in the Mexican Caribbean. Environ Biol Fish 45:351-361

Archer SK, Heppel SA, Semmens BX, Pattengill-Semmens CV, Bush PG, McCoy CM, Johnson BC (2012) Patterns of color phase indicate spawn timing at a Nassau grouper Epinephelus striatus spawning aggregation. Curr Zool 58:73-83

Beets J, Friedlander A (1999) Evaluation of a conservation strategy: a spawning aggregation closure for red hind, Epinephelus guttatus, in the US Virgin Islands. Environ Biol Fish 55:91-98

Carter HJ (1989) Grouper sex in Belize. Nat Hist October: 60-69

Claro R, Lindeman K (2003) Spawning aggregation sites of snapper and grouper species (Lutjanidae and Serranidae) on the insular shelf of Cuba. Gulf Caribb Res 14:91-106

Coleman R (2011) Nassau grouper spawning aggregations at Northeast Point, Glover's Reef Marine Reserve. Report. Wildlife Conservation Society, Belize City

Colin PL (1992) Reproduction of Nassau grouper, Epinephelus striatus (Pisces: Labroidei) and its relationship to environmental conditions. Environ Biol Fish 34:357-377

Colin PL (2012) Timing and location of aggregation and spawning in reef fishes. In: Sadovy de Mitcheson Y, Colin PL (eds) Reef fish spawning aggregations: research and management. Fish \& Fisheries Series, Vol 35. Springer, New York, NY, p 117-158

Cornish A, Eklund AM (2003) Epinephelus striatus. In: 2011 IUCN Red List of Threatened Species. Version 2011.2. www.iucnredlist.org (accessed 7 April 2012)

Craig MT, Hastings PA (2007) A molecular phylogeny of the groupers of the subfamily Epinephelinae (Serranidae) with a revised classification of the Epinephelini. Ichthyol Res 54:1-17

Domeier ML, Colin PL (1997) Tropical reef fish spawning aggregations: defined and reviewed. Bull Mar Sci 60: 698-726

Fish MP, Mowbray WH (1970) Sounds of western North Atlantic fishes. Johns Hopkins Press, Baltimore, MD

García-Sais JR, Castro R, Sabater-Clavell J, Carlo M, Esteves R (2007) Characterization of benthic habitats and associated reef communities at Bajo de Sico Seamount, Mona Passage, Puerto Rico. Final Report to Caribbean Fisheries Management Council, Puerto Rico 
Hazlett B, Winn HE (1962) Sound producing mechanism of the Nassau grouper, Epinephelus striatus. Copeia 1962: 447-449

Heyman WD, Kjerfve B (2008) Characterization of transient multi-species reef fish spawning aggregations at Gladden Spit, Belize. Bull Mar Sci 83:531-551

Kadison E, Nemeth R, Blondeau J, Smith T, Calnan J (2010) Nassau grouper (Epinephelus striatus) in St. Thomas, US Virgin Islands, with evidence for a spawning aggregation recovery. Proc Gulf Caribb Fish Inst 62:273-279

Kline RJ, Khan IA, Holt GJ (2011) Behavior, color change and time for sexual inversion in the protogynous grouper (Epinephelus adscensionis). PLoS ONE 6:e19576

Lobel PS (2002) Diversity of fish courtship and spawning sounds and application for monitoring reproduction. J Acoust Soc Am 112:2201-2202

> Lobel PS, Kerr LM (1999) Courtship sounds of the Pacific damselfish, Abudefduf sordidus (Pomacentridae). Biol Bull (Woods Hole) 197:242-244

Locascio JV, Mann DA (2011) Diel and seasonal timing of sound production by black drum (Pogonias cromis). Fish Bull 109:327-338

Mann DA, Lobel PS (1998) Acoustic behavior of the damselfish Dascyllus albisella: behavioral and geographic variation. Environ Biol Fish 51:421-428

Mann DA, Ma WLD, Lobel PS (2002) Sound production by the toadfish Sanopus astrifer. J Acoust Soc Am 112: 2202-2203

Mann DA, Locascio JV, Coleman FC, Koenig CC (2009) Goliath grouper Epinephelus itajara sound production and movement patterns on aggregation sites. Endang Species Res 7:229-236

Mann D, Locascio J, Schärer M, Nemeth M, Appeldoorn R (2010) Sound production by red hind Epinephelus guttatus in spatially segregated spawning aggregations. Aquat Biol 10:149-154

Moulton JM (1958) The acoustical behavior of some fishes in the Bimini area. Biol Bull (Woods Hole) 114:357-374

Myrberg AA, Mohler M, Catala J (1986) Sound production by males of a coral reef fish (Pomacentrus partitus): its significance to females. Anim Behav 34:913-923

Myrberg AA, Ha SJ, Shamblott MJ (1993) The sounds of bicolor damselfish (Pomacentrus partitus): predictors of body size and a spectral basis for individual recognition and assessment. J Acoust Soc Am 94:3067-3070

Nelson MD, Koenig CC, Coleman FC, Mann DA (2011) Sound production of red grouper Epinephelus morio on the West Florida Shelf. Aquat Biol 12:97-108

Editorial responsibility: Steven Cooke, Ottawa, Ontario, Canada
Nemeth RS (2005) Population characteristics of a recovering US Virgin Islands red hind spawning aggregation following protection. Mar Ecol Prog Ser 286:81-97

Nemeth RS, Kadison S, Herzlieb S, Blondeau J, Whiteman WA (2006) Status of a yellowfin (Mycteroperca venenosa) grouper spawning aggregation in the US Virgin Islands with notes on other species. Proc Gulf Caribb Fish Inst 57:543-558

Olsen DA, La Place JA (1978) A study of Virgin Islands grouper fishery based on a breeding aggregation. Proc Gulf Caribb Fish Inst 31:130-144

Rowell TJ, Schärer MT, Appeldoorn RS, Nemeth MI, Mann DA, Rivera JA (2012) Sound production as an indicator of red hind density at a spawning aggregation. Mar Ecol Prog Ser 462:241-250

Sadovy Y (1995) The case of the disappearing grouper: Epinephelus striatus the Nassau grouper in the Caribbean and western Atlantic. Proc Gulf Caribb Fish Inst 45:5-22

Sadovy Y, Domeier M (2005) Are aggregation-fisheries sustainable? Reef fish fisheries as a case study. Coral Reefs 24:254-262

Sadovy Y, Eklund A (1999) Synopsis of biological data on the Nassau grouper, Epinephelus striatus (Bloch, 1792), and the jewfish, E. itajara (Lichtenstein, 1822). NOAA Tech Rep NMFS 146. US Department of Commerce, Seattle, WA

Sadovy de Mitcheson Y, Craig M, Bertoncini A, Carpenter K and others (2012) Fishing groupers towards extinction: a global assessment of threats and extinction risks in a billion dollar fishery. Fish Fish 448:93-104

> Sala E, Ballesteros E, Starr RM (2001) Rapid decline of Nassau grouper spawning aggregations in Belize: fishery management and conservation needs. Fisheries 26: 23-31

> Schärer MT, Nemeth MI, Mann DA, Locascio JV, Appeldoorn RS, Rowell TJ (2012) Sound production and reproductive behavior of yellowfin grouper, Mycteroperca venenosa (Serranidae) at a spawning aggregation. Copeia 2012:135-144

Veerappan N, Pandi V, Balasubramanian T (2009) Sound production behaviour in a marine croaker fish, Kathala axillaris (Cuvier). World J Fish Mar Sci 1:206-211

Whaylen L, Bush P, Johnson B, Luke KE and others (2006) Aggregation dynamics and lessons learned from five years of monitoring at a Nassau grouper (Epinephelus striatus) spawning aggregation in Little Cayman, Cayman Islands. Proc Gulf Caribb Fish Inst 59:413-421

Submitted: May 23, 2012; Accepted: August 23, 2012

Proofs received from author(s): October 26, 2012 